\title{
Effect of pyrolysis conditions on the properties of carbonaceous nanofibers obtained from freeze-dried cellulose nanofibers
}

\author{
Ehsan Jazaeri · Takuya Tsuzuki
}

Received: 30 September 2012/ Accepted: 24 December 2012/Published online: 10 January 2013

(C) Springer Science+Business Media Dordrecht 2013

\begin{abstract}
Carbonaceous nanofibers (CsNFs) were produced by pyrolysis of cellulose nanofibers synthesised from wood pulp using a top-down approach. The effects of heat treatment conditions on the thermal, morphological, crystal and chemical properties of the CsNFs were investigated using TGA, SEM, XRD and FT-IR, respectively. The results showed that heat treatment conditions around the thermal decomposition temperature of cellulose greatly influence the morphology of resulting materials. Slow heating rates $\left(1{ }^{\circ} \mathrm{C} / \mathrm{min}\right)$ between 240 and $400{ }^{\circ} \mathrm{C}$ as well as prolonged isothermal heat treatment $(17 \mathrm{~h})$ at $240{ }^{\circ} \mathrm{C}$ were necessary to avoid destruction of the original fibrous morphology in carbonized nanofibers. On the other hand, such heat treatment had little effect on micron sized fibers. The optimized heat treatment conditions led to the release of oxygen and hydrogen from cellulose before thermal breakdown of glycosidic rings, which in turn prevented depolymerization and tar formation, resulting in the preservation of the fibrous morphology.
\end{abstract}

Keywords Carbon nanofiber - Cellulose nanofiber . Freeze drying · Pyrolysis · Heat treatment

E. Jazaeri · T. Tsuzuki $(\bowtie)$

Australian Future Fibers Research and Innovation Centre, Institute for Frontier Materials, Deakin University,

Waurn Ponds, VIC 3216, Australia

e-mail: t.tsuzuki@research.deakin.edu.au

\section{Introduction}

Graphitized carbon nanofibers (CNFs) consist of long graphitic layers that are oriented along the fiber axis and stacked up perpendicular to the fiber axis (Chung 1994; Morgan 2005a, b). Due to their unique mechanical and electrical properties, CNFs find many applications including nanocomposites in automotive and aerospace ( $\mathrm{Ci}$ et al. 2000; Sevilla and Fuertes 2010; Xie et al. 2009) and sensors in electronics (Tran et al. 2009). To date, various methods have been developed to obtain CNFs, including chemical vapour deposition, electrospinning and pyrolysis (Uchida et al. 2006). Among them, pyrolysis is a relatively simple approach which has the potential to reduce the costs and environmental impacts of CNF production (Guilminot et al. 2007).

In fact, most of the commercial carbon fibers $(\mathrm{CFs})$ with micron size diameters are produced by pyrolysis. However, the precursors are normally made from fossil fuels, such as polyacrylonitrile (Morgan 2005c) or oil-/coal-based pitch (Morgan 2005d). Viscose rayon precursors have also been used while prepared by some hazardous chemicals to enhance the properties. Hence the use of these precursors poses environmental and cost-related concerns. Despite this drawback in the current $\mathrm{CF}$ production, the investigation of $\mathrm{CF}$ production by the pyrolysis of renewable materials has rarely appeared in the literature (Nogi et al. 2010; Ishida et al. 2004). 
Cellulose is a renewable raw material and widely available on earth with the estimated yearly-production of $10^{10}$ tons (Nogi et al. 2010; Salmon and Hudson 1997). It consists of long linear homopolymers of (1-4)-linked $\beta$-D-glucopyranose units with the formula of $\left(\mathrm{C}_{6} \mathrm{H}_{10} \mathrm{O}_{5}\right)_{n}(\mathrm{n}=$ degree of polymerization of glucose) that are combined to form highly ordered cellulosic chains (Oh et al. 2005). These chains form parallel nanoscale fibrillar structures which again link together via strong hydrogen bonds to form cellulose fibers. Due to its high carbon content $(44.4 \%)$ and natural fibrous structures, cellulose is a good candidate as an eco-friendly raw material for CNF production by pyrolysis (Khezami et al. 2005).

Although the pyrolysis of bulk cellulosic materials has been extensively investigated, most of the studies were focused on the production of energy or bulk char rather than fibers (Ishida et al. 2004; Agoda et al. 2010; Broido and Yow 1977; Brunner and Roberts 1980; Cagnon et al. 2009; Chen et al. 2011; Gaur and Reed 1994; Kim et al. 2001; Sekiguchi et al. 1983; Tang and Bacon 1964; Yoshino et al. 1990). The formation of CFs by pyrolysis of native cellulose is more challenging than the formation of activated carbon from cellulose, as the fibrous structure needs to be preserved during carbonization. In particular, the formation of volatile and often sticky tar (levoglucosan) should be carefully avoided.

The pyrolysis of cellulose nanofibers (CellNFs) is expected to result in the formation of CNFs. However, little research has been reported on the production of nano-scale CFs by the pyrolysis of CellNFs. It is expected that the molecular and morphological properties of precursors strongly affect those of the pyrolysed carbon material (Yoshino et al. 1990). Ishida et al. (2004) investigated the carbonization of freeze-dried bacterial and tunicate CellNFs and found that the carbon residue retained its fibrous morphology by using $\mathrm{HCl}$ as a pyrolytic atmosphere and a pretreatment chemical. Another study showed that the effect of surface area and thermal stability of chitin and wood CellNFs was considered to be the main factors in altering the fibrous morphology in the resultant carbon residues (Morgan 2005c). However, these studies did not report successful retention of the fibrous structure of softwood-based CellNFs in the carbon residue.

Recently, we reported the possibility of fabricating carbonaceous nanofibers (CsNFs) by pyrolysis of freeze-dried CellNFs that were obtained from softwood pulp without the use of chemicals or catalysts (Jazaeri et al. 2011). It was shown that a freeze drying method provides sufficient spatial distance between CellNFs to prohibit the formation of chemical bonding between carbon chains of the neighboring nanofibers during pyrolysis. However, fiber damage was still reported occurring, and keeping the fibrous structure after carbonization of CellNFs remained a big challenge. The retention of fibrous structures during pyrolysis is not a trivial task in nano-dimension, because atoms and molecules do not need to diffuse long distances to alter the fibrous structures. In addition to the spatial distance between CellNFs, pyrolysis conditions are expected to greatly influence the morphological and structural properties of the CsNFs. Nevertheless, there is no report to date as to how heat treatment conditions influence the formation of CNFs during the pyrolysis of CellNFs.

In this study, the effects of heat treatment conditions of CellNFs on the properties of resulting CsNFs were investigated. CellNFs were obtained from softwood pulp using a top-down approach. The effects of heating rate, maximum temperature and residence time on the chemical, crystal, thermal and morphological properties of the CsNFs were studied.

According to ISO Standard 472:1999, carbon fiber is defined as 'fiber containing at least $90 \%$ by mass of carbon, obtained by pyrolysis of organic-fiber precursors'. In this study, the quantity of residual oxygen in the heat treated samples was not analysed. Hence, in order to avoid potential confusion arising from the terminology, the term "carbonaceous nanofiber (CsNF)' is used instead of 'carbon nanofibers' in this paper to describe the fibers heat treated at the moderate temperature of $400{ }^{\circ} \mathrm{C}$.

\section{Experimental}

\section{CellNF preparation}

Dried softwood pulp (NIST standard material RM 8495 Northern Softwood Bleached Kraft Pulp) was used to prepare CellNFs. The procedure to prepare CellNFs has been described elsewhere (Jazaeri et al. 2011; Zhang et al. 2010). Briefly, a pulp suspension in water was ball-milled for 90 min with zirconia balls of $0.5 \mathrm{~mm}$ in diameter. The resulting CellNF suspension 
was then freeze-dried by first stirring in liquid nitrogen and then vacuum-dried for $24 \mathrm{~h}$ using a Labconco Freeze-Dryer. In order to study the effect of fiber diameter, the dried wood pulp was also carbonized at $<900{ }^{\circ} \mathrm{C}$ without defibrillation.

\section{Pyrolysis}

In order to study the effects of heat treatment conditions, 13 samples were prepared under different conditions using a Lindberg/Blue tube furnace. The pyrolysis conditions for each sample are listed in Table 1 . The pyrolysis was carried out under $\mathrm{N}_{2}$ gas with the gas flow rate of $70 \mathrm{~mL} / \mathrm{min}$ from the starting temperature of $20{ }^{\circ} \mathrm{C}$. Cellulose undergoes thermal decomposition in three simplified stages: (1) physical dehydration of the absorbed water $\left(25-170{ }^{\circ} \mathrm{C}\right)$, (2) internal dehydration from glycosidic rings $\left(170-240{ }^{\circ} \mathrm{C}\right.$ ) and (3) breakdown of the glycosidic rings and formation of volatile gases and a carbon char (240-400 ${ }^{\circ} \mathrm{C}$ ) (Morgan 2005e). Therefore, the pyrolysis conditions in the three critical stages, 25-170, 170-240 and $240-400{ }^{\circ} \mathrm{C}$, were separately studied.

\section{Characterization}

The morphological study of the nanofibrous samples was undertaken using a Supra 55 VP scanning electron microscope (SEM), while the carbonized pulp was studied using a Jeol Neoscope JCM5000 SEM. The samples were mounted on a carbon tape; a carbon coating was applied and vacuum-dried for minimum $5 \mathrm{~h}$ before being placed in the SEM chamber. The thermal behaviour of CellNFs was studied using a Netzsch 407 PC Luxx simultaneous thermogravimetry differential-scanning-calorimetry (TG/DSC) instrument with the NETZSCH Proteus analysis software. The samples were placed in alumina crucibles and heated with $10^{\circ} \mathrm{C} / \mathrm{min}$ under $\mathrm{N}_{2}$ atmosphere with $10 \mathrm{~mL} / \mathrm{min}$ flow rate. The crystallinity of the nanofiber samples was studied using a Panalytical X-ray diffraction (XRD) instrument with $2 \theta$ between $5^{\circ}$ and $80^{\circ}$, step size of $0.02^{\circ}$, time per step of $1 \mathrm{~s}$, and $\mathrm{Cu} \mathrm{k} \alpha$ radiation generated at a voltage of $40 \mathrm{kV}$ and a current of $30 \mathrm{~mA}$. Crystallite sizes, $D_{c r}$, were calculated using the Bragg and Scherrer equation:

$D_{c r}=\frac{K \lambda}{\beta \cdot \cos \theta}$

where $K$ is the Scherrer constant (0.94), $\lambda$ is the wavelength $(0.1542 \mathrm{~nm}), \beta$ is the peak width in radians at an intensity equal to half the maximum intensity (FWHM) and $\theta$ is the Bragg angle. For cellulose samples before carbonization, the main peak at $22.5^{\circ}$ was used to calculate the crystallite size. The crystallinity index of cellulose, $I$, was estimated using the Segal method (Oh et al. 2005):

Table 1 Heat treatment conditions

\begin{tabular}{|c|c|c|c|c|c|}
\hline \multirow[t]{2}{*}{ Sample ID } & \multirow[t]{2}{*}{ Heating rate $\left({ }^{\circ} \mathrm{C} / \mathrm{min}\right)$} & \multicolumn{2}{|c|}{ Target temperature 1} & \multirow[t]{2}{*}{ Heating rate $\left({ }^{\circ} \mathrm{C} / \mathrm{min}\right)$} & \multirow{2}{*}{$\begin{array}{l}\text { Target temperature } 2 \\
\text { Temp. }\left({ }^{\circ} \mathrm{C}\right)\end{array}$} \\
\hline & & Temp. $\left({ }^{\circ} \mathrm{C}\right)$ & Residence time (h) & & \\
\hline NF1 & 10 & 170 & 0 & - & - \\
\hline NF2 & 10 & 170 & 2 & - & - \\
\hline NF3 & 10 & 170 & 3 & - & - \\
\hline NF4 & 10 & 170 & 0 & 1 & 240 \\
\hline NF5 & 10 & 170 & 0 & 2 & 240 \\
\hline NF6 & 10 & 170 & 0 & 10 & 240 \\
\hline NF7 & 10 & 240 & 1 & - & - \\
\hline NF8 & 10 & 240 & 3 & - & - \\
\hline NF9 & 10 & 240 & 17 & - & - \\
\hline NF10 & 10 & 240 & 17 & 1 & 400 \\
\hline NF11 & 10 & 240 & 17 & 10 & 400 \\
\hline NF12 & 10 & 240 & 1 & 1 & 400 \\
\hline Pulp & 20 & 900 & - & - & - \\
\hline
\end{tabular}


$I=\frac{I_{\max }-I_{\min }}{I_{\max }}$

where $I_{\max }$ is the maximum intensity of the peak at $22.5^{\circ}$ and $I_{\min }$ is the peak intensity of the amorphous fraction represented by the diffraction intensity at $19^{\circ}$. The analysis of chemical bonds in heat treated samples was undertaken using a Bruker Vertex 70 FT-IR spectrometer with the OPUS 5.5 analysis software in absorbance mode.

\section{Results}

Thermal analysis

Figure 1a shows the TG/DSC curves of freeze-dried CellNFs. Below $170{ }^{\circ} \mathrm{C}$, the mass loss was insignificant $(<1 \%)$. Upon further heating to $240{ }^{\circ} \mathrm{C}$, the mass loss started to increase due to internal dehydration and formation of water (Tang and Bacon 1964).
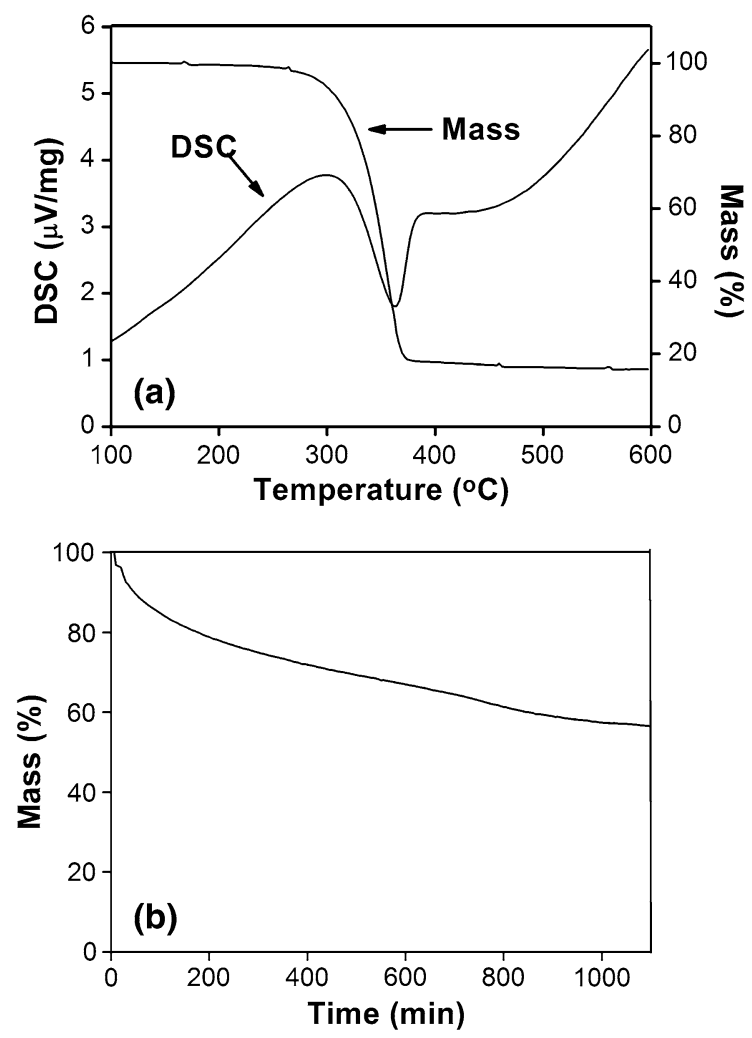

Fig. 1 a TG/DSC curves of CellNFs and b mass loss at $240{ }^{\circ} \mathrm{C}$ as a function of holding time
The DSC curve in Fig. 1a shows a peak at $360{ }^{\circ} \mathrm{C}$ due to an endothermic reaction associated with the breakage of glycosidic rings of cellulose. CellNFs lost $81 \%$ of their weight between 240 and $370{ }^{\circ} \mathrm{C}$. Further heating above $370{ }^{\circ} \mathrm{C}$ caused negligible mass loss, indicating the completion of the decomposition of cellulose and formation of a carbonaceous residue above $370{ }^{\circ} \mathrm{C}$.

Figure $1 \mathrm{~b}$ shows the mass loss of the sample during isothermal heat treatment at $240{ }^{\circ} \mathrm{C}$. After heat treatment for $1,100 \mathrm{~min}$, the mass loss nearly reached a plateau during which $\sim 40 \%$ of its weight was lost.

\section{Morphology}

Figure 2 shows SEM images of the samples treated under various heat treatment conditions (NF9-NF12 and pulp). The samples NF1-NF9 and the original freeze-dried CellNFs had morphologies identical with NF9, where fibers with diameters of $\sim 50 \mathrm{~nm}$ and high aspect ratios (ratio of fiber length to diameter) were closely entangled in a network structure. The samples NF10-NF12 underwent carbonization and their appearance changed from a white spongy mass to a black char (Fig. 3). The SEM images of NF11 and NF12 show that, during carbonization, the fibers were damaged by fusing together and forming bundles of carbon char rather than fibers. Although some fibers retained their fibrous structures, they did not retain their original high aspect ratios. On the other hand, the SEM image of NF10 shows the morphology similar to its CellNF precursor with high aspect ratios. The SEM image of carbonized pulp shows that the heat treatment of micron size pulp fibers with high heating rates does not affect the fibrous morphology after carbonization except some minor breakage. The slight breakage shown in the SEM image of carbonized pulp was induced during the preparation of SEM specimen.

\section{Crystal structure}

The crystal structure of the precursor cellulose is expected to influence the decomposition process and subsequently the structure of resultant carbonaceous materials (Morgan 2005e). This is due to the fact that any changes in the crystalline structure would alter the cellulose decomposition process (Morgan 2005e). Figure 4 shows XRD patterns of precursor CellNFs, NF9, NF10 and carbonized pulp. The XRD pattern of 

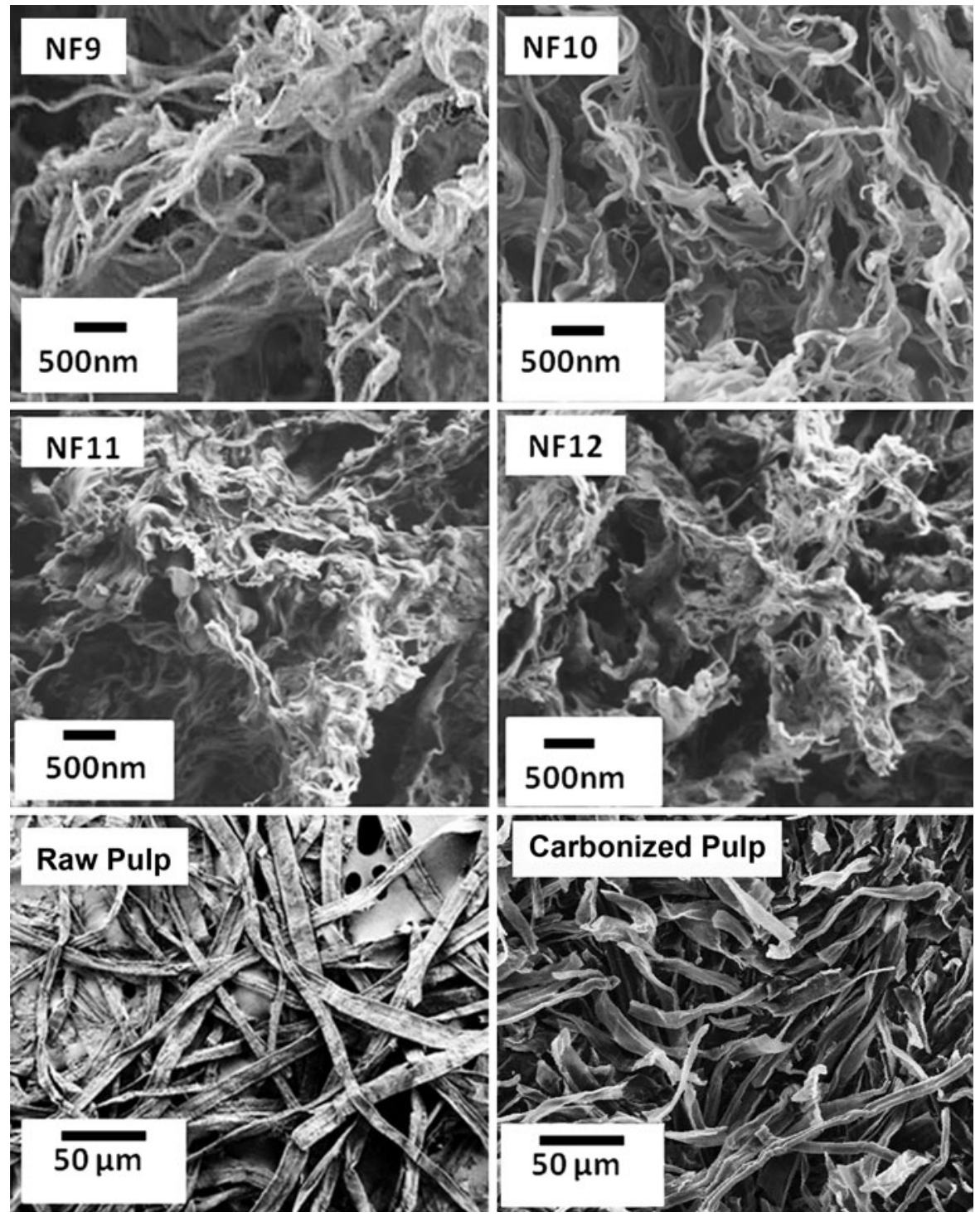

Fig. 2 SEM images of the freeze-dried CellNFs and carbon residues

CellNFs shows the typical cellulose-I crystal structure. The XRD graphs of samples NF1 to NF8 resembled the spectrum of NF9, indicating that the cellulose-I crystal structure was largely retained under these heat treatment conditions below $240{ }^{\circ} \mathrm{C}$.

Table 2 shows the crystalline size and the degree of crystallinity for samples NF1-NF9. The XRD curve of the freeze-dried CellNFs shows that the crystallinity of the precursor is $63 \%$, slightly lower than that of the pulp raw material $(73 \%)$ due to the mechanical treatment (ball milling) to obtain CellNFs. Heat treatments up to $240{ }^{\circ} \mathrm{C}$ (NF1-NF9) did not drastically alter the crystallinity. The results indicate that, irrespective of different heating rates and holding times, heat treatment up to $240{ }^{\circ} \mathrm{C}$ did not influence the basic crystallite properties of CellNFs. It is interesting to note that, in NF9, cellulose-I crystal structure was retained even after the mass loss of $\sim 40 \%$. Similar results were also reported by Davidson and Losty (1963).

As shown in Fig. 4, the XRD pattern of carbonized micron-size pulp fibers is nearly identical to that of amorphous carbon (Morgan 2005e). On the other hand, the XRD pattern of NF10 appears different from the cellulose-I structure and also from amorphous 

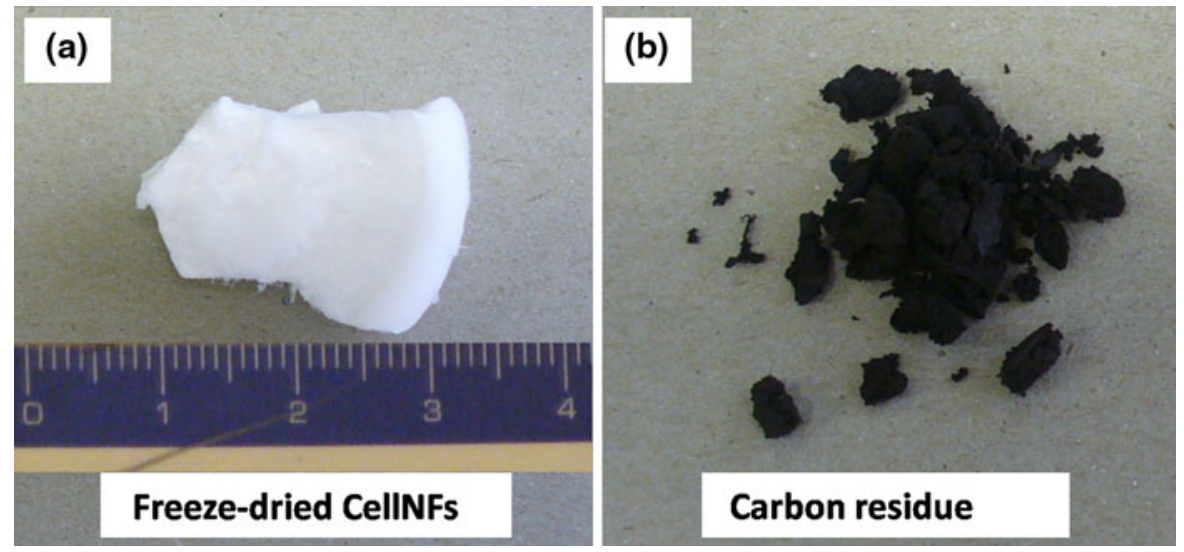

Fig. 3 Appearance of $\mathbf{a}$ freeze-dried CellNFs and $\mathbf{b}$ carbon residue

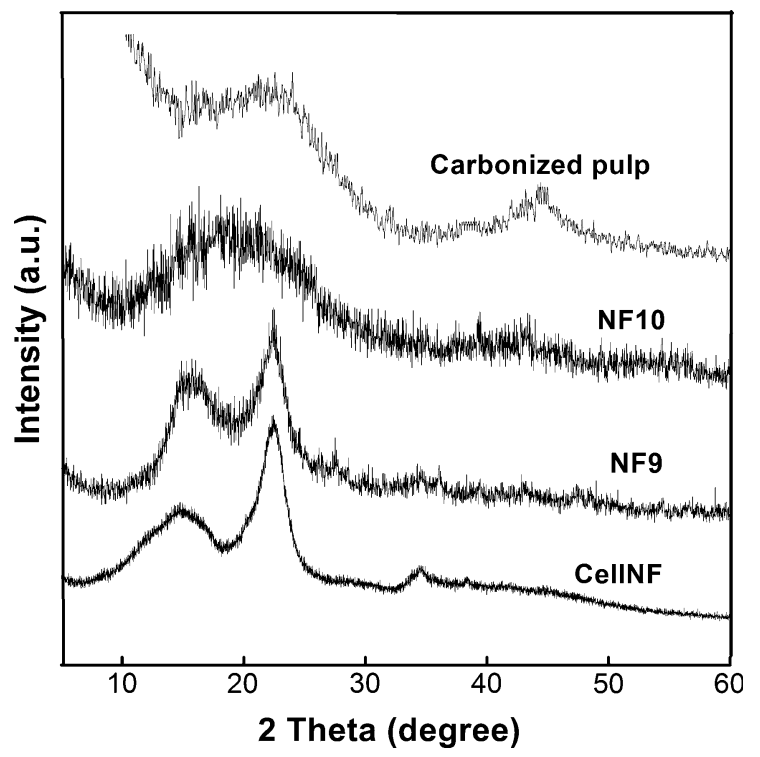

Fig. 4 XRD spectra of heat treated samples

carbon. The result suggests that, after heat treatment of CellNFs above $370{ }^{\circ} \mathrm{C}$, the cellulose-I structure was destroyed but an intermediate phase between cellulose and inorganic amorphous carbon was formed.

Chemical analysis

Figure 5a shows the FT-IR spectra of the precursor CellNFs, NF9, NF10, NF12 and carbonized pulp. The spectra of samples NF1-NF8 resembled the spectrum of CellNFs. The bands at 1,025 and $1,050 \mathrm{~cm}^{-1}$ were assigned to the vibration of $\mathrm{C}-\mathrm{OH}$ bonds at the 1 st and 2nd alcohols in the glucose rings, and $1,112 \mathrm{~cm}^{-1}$ was assigned to $\mathrm{C}-\mathrm{O}-\mathrm{C}$ glycoside links in the cellulose chain
Table 2 Crystallite size (peak at $22.5^{\circ}$ ) and the degree of crystallinity

\begin{tabular}{lll}
\hline Sample ID & Crystallite size $(\mathrm{nm})$ & Crystallinity $(\%)$ \\
\hline Softwood pulp & 3.75 & 73 \\
Freeze-dried CellNF & 3.70 & 63 \\
NF1 & 3.86 & 59 \\
NF2 & 3.38 & 59 \\
NF3 & 3.86 & 63 \\
NF4 & 3.47 & 54 \\
NF5 & 3.86 & 63 \\
NF6 & 4.06 & 57 \\
NF7 & 4.05 & 62 \\
NF8 & 3.80 & 60 \\
NF9 & 3.20 & 60 \\
\hline
\end{tabular}

(Fig. 5b) (Oh et al. 2005; Nelson and O'connor 1964a, b; Cao and Tan 2002). It is evident that the relative intensities of the peaks at 1,025 and $1,050 \mathrm{~cm}^{-1}$, compared to the peak at $1,112 \mathrm{~cm}^{-1}$, were reduced in NF-9 from that in CellNFs. This indicates that, after isothermal heat treatment at $240{ }^{\circ} \mathrm{C}$ for $17 \mathrm{~h}$, much of the $\mathrm{OH}$ bonds were removed, possibly by dehydration processes, while glycoside link remained intact.

The FT-IR spectra of NF10 and NF12 were different from that of NF9, confirming that NF10 and NF12 were no longer cellulosic. After the thermal decomposition of cellulose, much of the oxygen- and hydrogen-related peaks between 1,000 and $1,500 \mathrm{~cm}^{-1}$ has been removed. Instead, new bands appeared at 1,603 and $1,703 \mathrm{~cm}^{-1}$. The peak at $1,603 \mathrm{~cm}^{-1}$ is associated with the $\mathrm{C}=\mathrm{C}$ stretching vibration of the aromatic rings (Shin et al. 1997; Zhou et al. 2007) and hence indicates the 

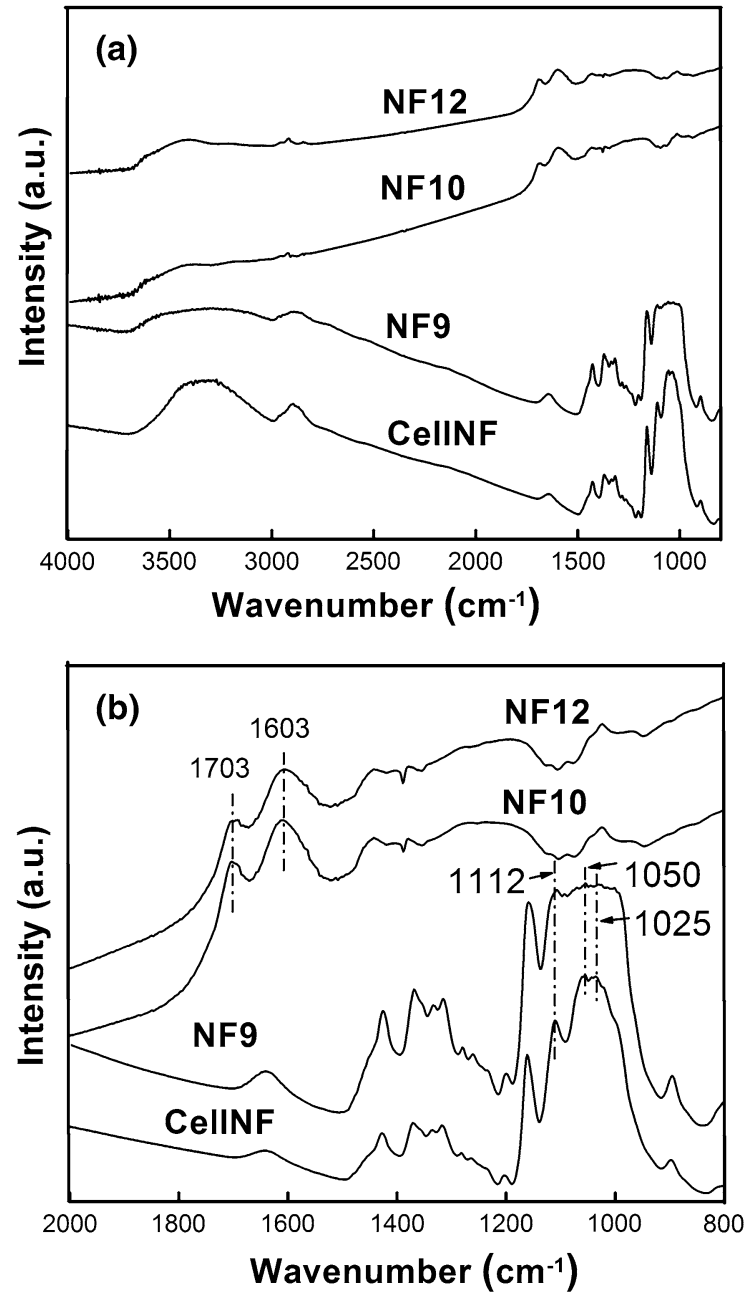

Fig. 5 FT-IR spectra of heat treated samples; a $4,000-800 \mathrm{~cm}^{-1}$, b $2,000-800 \mathrm{~cm}^{-1}$

formation of aromatic rings in NF10 and NF12. The peak at $1,703 \mathrm{~cm}^{-1}$ is attributed to $\mathrm{C}=\mathrm{O}$ stretching of non-aromatic bonds (Shin et al. 1997; Zhou et al. 2007) implying the presence of oxygen even after the decomposition of cellulose-I structure.

\section{Discussion}

All the results from TG/DSC, SEM, XRD and FT-IR studies indicated that the residence time at $170{ }^{\circ} \mathrm{C}$ and heating rate from 170 to $240{ }^{\circ} \mathrm{C}$ did not induce any change in the crystallinity and morphology of CellNFs. However, residence time at $240{ }^{\circ} \mathrm{C}$ and heating rate from 240 to $400{ }^{\circ} \mathrm{C}$ greatly influenced the morphology of the resulting CNFs. Longer holding time at $240{ }^{\circ} \mathrm{C}$ and slower heating rate from 240 to $400{ }^{\circ} \mathrm{C}$ were necessary to preserve the original fibrous structures of CellNFs in CsNFs.

TG data showed that extensive mass loss occurred at $240{ }^{\circ} \mathrm{C}$. The mass loss reached $\sim 40 \%$ after $17 \mathrm{~h}$ of isothermal heating. The FT-IR results indicate that the mass loss is mainly associated with the loss of $\mathrm{OH}$ groups and hence is caused by intra- or inter-chain dehydration. This result is consistent with the report by Tang et al. where the water is found to be the major decomposition product at the temperature below $240{ }^{\circ} \mathrm{C}$ (Tang and Bacon 1964).

An intra-molecular dehydration model between two $\mathrm{OH}$ groups has frequently been used for explaining the mass loss of cellulose below $300{ }^{\circ} \mathrm{C}$ (Morgan 2005e). This model predicts the formation of $\mathrm{C}=\mathrm{C}$ and $\mathrm{C}=\mathrm{O}$ bonds (Fig. 6). However, as can be seen in the FT-IR spectrum of NF9, $\mathrm{C}=\mathrm{C}$ or $\mathrm{C}=\mathrm{O}$ bands in the aromatic rings did not appear after heat treatment for $17 \mathrm{~h}$ at $240{ }^{\circ} \mathrm{C}$. The result implies that the dehydration process occurred mainly between the inter-chain $\mathrm{OH}$ groups, but not between the $\mathrm{OH}$ groups in the same pyranose rings.

In cellulose crystals, straight cellulose chains are interconnected with other chains through strong hydrogen bonds between the $\mathrm{OH}$ groups. Dehydration at $240{ }^{\circ} \mathrm{C}$ may result in inter-chain covalent bonding between cellulose single chains and help preserve fibrous structures upon carbonization. In addition, the removal of $\mathrm{OH}$ from $-\mathrm{CH}_{2} \mathrm{OH}$ groups may prevent (1) the chain scission at glycoside links and (2) the formation of volatile and viscous tar (levoglucosan)
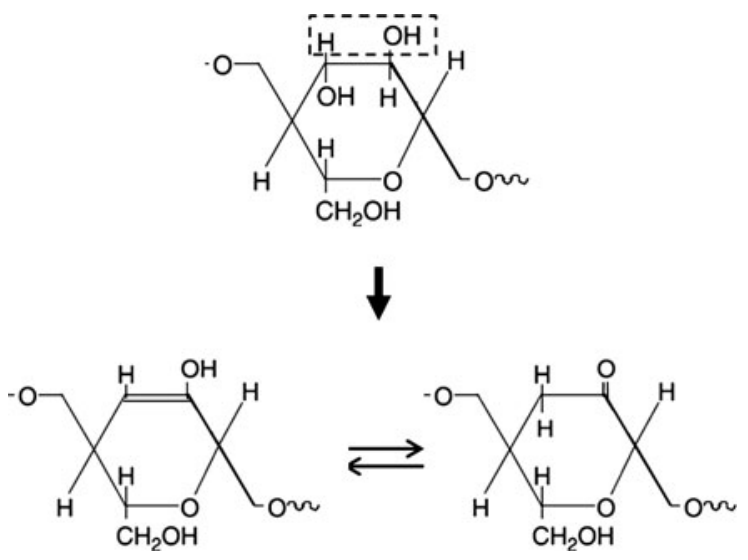

Fig. 6 Intramolecular dehydration in cellulose chains 
(Fig. 7), which may play a critical role in preserving the original fibrous structures (Fig. 8).

The D-glucose unit in cellulose has $3 \mathrm{OH}$ groups and their loss is equivalent to the mass loss of $\sim 33 \%$. This value is smaller than the observed mass loss of $40 \%$ during the isothermal heating at $240{ }^{\circ} \mathrm{C}$. Hence, apart from dehydration, the evolution of some gaseous species such as $\mathrm{CO}, \mathrm{CO}_{2}$ and $\mathrm{CH}_{4}$ may have occurred at $240{ }^{\circ} \mathrm{C}$, without affecting the crystal structure of cellulose. Further study is required to identify these gases evolved during the isothermal heat treatment at $240{ }^{\circ} \mathrm{C}$ by, for example, FT-IR or mass spectroscopy (Shen and Gu 2009).

The SEM images of NF10 and NF11 show that, even after dehydration at $240{ }^{\circ} \mathrm{C}$ for $17 \mathrm{~h}$, fast heating rate can still destroy the original fibrous structure. This result suggests that the removal of remaining oxygen in the pyranose rings and glycoside links could lead to depolymerization at fast heating rates (e.g. $10^{\circ} \mathrm{C} /$ min). The slow heating rate $\left(1{ }^{\circ} \mathrm{C} / \mathrm{min}\right)$ may provide the carbon atoms with sufficient time to diffuse inside the nanofibers and form aromatic rings without
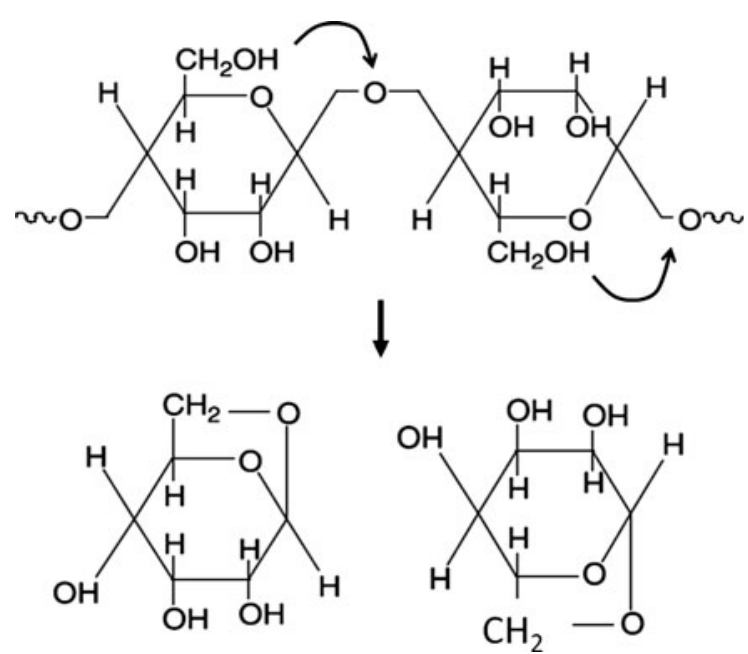

Fig. 7 Formation of levoglocosan associated with depolymerization

Fig. 8 Model of cellulose pyrolysis (Antal et al. 1980) causing morphological damages. In addition, it has been reported that more oxygen and hydrogen can escape the cellulosic chains during carbonization if slower heating rates are applied between 240 and $350{ }^{\circ} \mathrm{C}$ (Yoshino et al. 1990; Fitzer 1990). This helps reduce oxygen-to-carbon ratio within the carbon structure, contributing to the preservation of fibrous structures in the carbonaceous residues.

The micron-sized pulp fibers did not show such changes in morphology even after heat treatment at a high heating rate without a long isothermal heating at $240{ }^{\circ} \mathrm{C}$. This insensitivity of micron-sized pulp fibers towards the heat treatment conditions is possibly due to the large (micron-scale) spatial distance between fibers. Nano-scale fibers are significantly more sensitive to these heat treatment conditions because the fibrous structures can be readily altered by atomic diffusion over much shorter distances in nanofibers than in micron-diameter fibers.

\section{Conclusion}

In this study, the effects of heat treatment conditions on carbonaceous nanofibers and their precursor cellulose nanofibers were investigated. Carbonaceous nanofibers were produced by the pyrolysis of cellulose nanofibers below $400{ }^{\circ} \mathrm{C}$. It is shown that heat treatment conditions around the thermal decomposition temperature greatly influence the morphological properties of carbon nanofibers. Longer holding time at $240{ }^{\circ} \mathrm{C}$ and slower heating rate from 240 to $400{ }^{\circ} \mathrm{C}$ were critical to preserve the original fibrous structures of the precursor cellulose nanofibers after pyrolysis. It was suggested that intermolecular dehydration was induced during the prolonged isothermal heat treatment at $240{ }^{\circ} \mathrm{C}$ and that the removal of $\mathrm{OH}$ groups reduced the chance of chain scission and the formation of tar. This in turn contributed to the retention of the original fibrous structure during carbonization between 240 and $400{ }^{\circ} \mathrm{C}$. Slow heating rate helps the

\footnotetext{
pyrolysis (Antal et al. 1980)
}

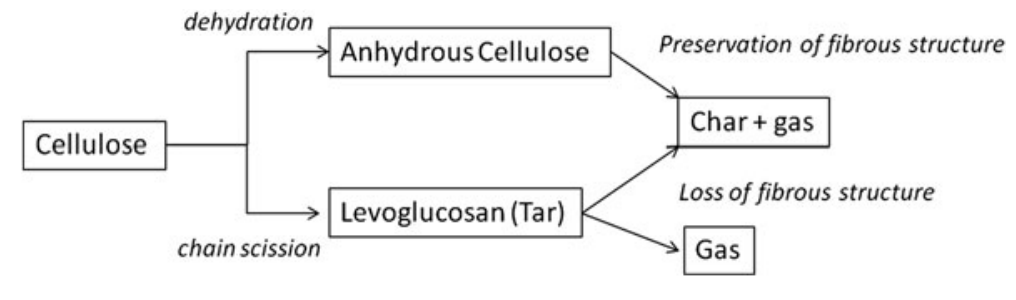


carbon chains to join neighbouring chains to form aromatic rings within the nanofiber boundaries without causing morphological damage to the nanofiber. In contrast, these heat treatment conditions had no influence on the morphology of resulting carbon residues in conventional micron-diameter fibers. In this context, the high sensitivity to the pyrolysis condition in the morphology of carbonaceous residue is a unique attribute of nano-scale fibers.

Acknowledgments The authors thank Dr. Warren Batchelor at the Australian Pulp and Paper Institute in Monash University for providing the dried softwood pulp. The authors also thank Professor Xungai Wang, Dr Rongliang He, Dr. Jinfeng Wang and Dr. Ehsan Bafekrpour for their kind support for this study.

\section{References}

Agoda TG, Durand S, Berot S, Blassel C, Gaillard C, Garnier C et al (2010) Rheological characterization of microfibrillated cellulose suspensions after freezing. Carbohydr Polym 80:677-686

Antal MJ, Friedman HL, Rogers FE (1980) Kinetics of cellulose pyrolysis in nitrogen and steam. Combust Sci Tech 21:141-152

Broido A, Yow H (1977) Resolution of molecular weight distributions in slightly pyrolysed cellulose using weibull function. J Appl Polym Sci 21:1677-1685

Brunner PH, Roberts PV (1980) The significance of heating rate on char yield and char properties in the pyrolysis of cellulose. Carbon 18:217-224

Cagnon BT, Xavier PY, Guillot A, Stoeckli F, Chambat GA (2009) Contributions of hemicellulose, cellulose and lignin to the mass and the porous properties of chars and steam activated carbons from various lignocellulosic precursors. Biores Tech 100:292-298

Cao Y, Tan HM (2002) Effects of cellulase on the modification of cellulose. Carbohydr Res 337:1291-1296

Chen W, Yu H, Liu Y, Chen P, Zhang M, Hai Y (2011) Individualization of cellulose nanofibers from wood using high-intensity ultrasonication combined with chemical pretreatments. Carbohydr Polym 83:1804-1811

Chung DDL (1994) Carbon fiber composites. ButterworthHeinemann, Boston

Ci LJ, Zhu HW, Wei BQ, Xu CL, Liang J, Wu DH (2000) Graphitization behavior of carbon nanofibers prepared by the floating catalyst method. Mater Lett 4:291-294

Davidson HW, Losty HHW (1963) The initial pyrolyses of celluloses. GEC J 30:22-28

Fitzer E (1990) Fibres. In: Figueiredo JL, Bernardo CA, Baker RTK, Huttinger KJ (ed) Carbon Fibers Filaments and Composites. Kluwer Academic, Dordrecht, pp 3-41

Gaur S, Reed TB (1994) Prediction of cellulose decomposition rates from thermogravimetric data. Biomass Bioenerg 7:61-67

Guilminot E, Fischer F, Chatenet M, Rigacci A, Berthon FS, Achard P et al (2007) Use of cellulose-based carbon aerogels as catalyst support for PEM fuel cell electrodes, electrochemical characterization. J Power Sources 166: 104-111

Ishida O, Kim DY, Kuga S, Nishiyama Y, Brown RM (2004) Microfibrillar carbon from native cellulose. Cellulose 11:475-480

Jazaeri E, Zhang L, Wang X, Tsuzuki T (2011) Fabrication of carbon nanofiber by pyrolysis of freeze-dried cellulose nanofiber. Cellulose 18:1481-1485

Khezami L, Chetouani A, Taouk B, Capart R (2005) Production and characterisation of activated carbon from wood components in powder: cellulose, lignin, xylan. Powder Tech 157:48-56

Kim DY, Nishiyama Y, Wada M, Kuga S (2001) Graphitization of highly crystalline cellulose. Carbon 39:1051-1056

Morgan P (2005a) Structure of the carbon atom. In: Carbon fibers and their composites. CRC Press, Boca Raton, pp 1-13

Morgan P (2005b) The forms of carbon. In: Carbon fibers and their composites. CRC Press, Boca Raton, pp 24-31

Morgan P (2005c) Carbon fiber production using a PAN precursor. In: Carbon fibers and their composites. CRC Press, Boca Raton, pp 185-267

Morgan P (2005d) Carbon fiber production using a pitch based precursor. In: Carbon fibers and their composites. CRC Press, Boca Raton, pp 295-324

Morgan P (2005e) Carbon fiber production using a cellulosic based precursor. In: Carbon fibers and their composites. CRC Press, Boca Raton, pp 269-294

Nelson ML, O'connor RT (1964a) Relation of certain infrared bands to cellulose crystallinity and crystal lattice type. Part I: spectra of lattice types I, II, III and of amorphous cellulose. J Appl Polym Sci 8:1311-1324

Nelson ML, O'connor RT (1964b) Relation of certain infrared bands to cellulose crystallinity and crystal lattice type. Part II: a new infrared ratio for estimation of crystallinity in celluloses I and II. J Appl Polym Sci 8:1325-1341

Nogi M, Kurosaki F, Yano H, Takano M (2010) Preparation of nanofibrillar carbon from chitin nanofibers. Carbohydr Polym 81:919-924

Oh SY, Yoo DI, Shin Y, Kim HC, Kim HY, Chung YS et al (2005) Crystalline structure analysis of cellulose treated with sodium hydroxide and carbon dioxide by means of X-ray diffraction and FTIR spectroscopy. Carbohydr Res 340:2376-2391

Salmon S, Hudson SM (1997) Crystal morphology, biosynthesis, and physical assembly of cellulose, chitin, and chitosan. J Macromol Sci R M C C37:199-276

Sekiguchi Y, Frye JS, Shafizadeh F (1983) Structure and formation of cellulosic chars. J Appl Polym Sci 28:3513-3525

Sevilla M, Fuertes AB (2010) Graphitic carbon nanostructures from cellulose. Chem Phys Lett 490:63-68

Shen DK, Gu S (2009) The mechanism for thermal decomposition of cellulose and its main products. Biores Tech 100:6496-6504

Shin S, Jang J, Yoon SH, Mochida I (1997) A study on the effect of heat treatment on functional groups of pitch based activated carbon fiber using FTIR. Carbon 35:17391743

Tang MM, Bacon R (1964) Carbonization of cellulose fibers-I: low temperature pyrolysis. Carbon 2:211-214 
Tran PA, Zhang LJ, Webster TJ (2009) Carbon nanofibers and carbon nanotubes in regenerative medicine. Adv Drug Deliver Rev 61:1097-1114

Uchida T, Anderson DP, Minus ML, Kumar S (2006) Morphology and modulus of vapor grown carbon nano fibers. J Mater Sci 41:5851-5856

Xie X, Goodell B, Zhang D, Nagle DC, Qian Y, Peterson ML et al (2009) Characterization of carbons derived from cellulose and lignin and their oxidative behavior. Biores Tech 100:1797-1802
Yoshino K, Matsuoka R, Nogami K, Yamanaka S, Watanabe K, Takahashi $M$ et al (1990) Graphite film prepared by pyrolysis of bacterial cellulose. J Appl Phys 68:1720-1725

Zhang L, Tsuzuki T, Wang X (2010) Preparation and characterization on cellulose nanofiber film. Mater Sci Forum 654-656:1760-1763

Zhou JH, Sui ZJ, Zhu J, Li P, Chen D, Dai YC (2007) Characterization of surface oxygen complexes on carbon nanofibers by TPD, XPS and FT-IR. Carbon 45:785-796 